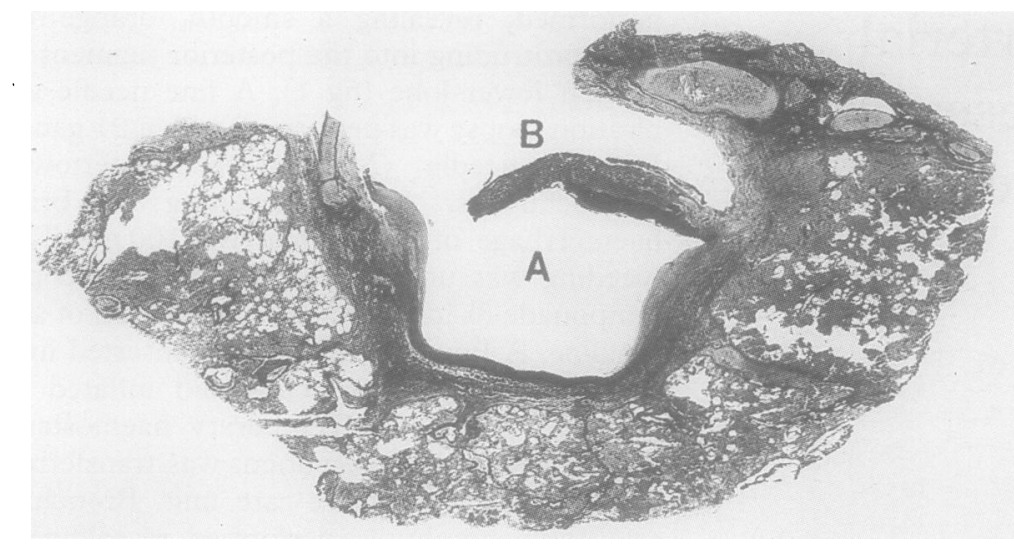

Figure 2 Paraffin embedded cross section of aneurysm at point of rupture into bronchial lumen; $A=$ aneurysmal lumen, $B=$ bronchial lumen. Elastic stain, magnification $\times 3$.

parenchyma and fail to impinge directly on a bronchus, it is not surprising that few have been detected by fibreoptic bronchoscopy.

We have found only one previous description of the bronchoscopic appearance of such a lesion. St Christov et $a l^{3}$ described a patient with a $2 \cdot 5-3 \mathrm{~cm}$ reddish, tumourlike mass filling the left main bronchus. This lesion bled spontaneously after a few seconds and resulted in the patient's death. Pathological examination revealed a bulbous aneurysm encasing the bronchus in a cuff-like fashion, with medial necrosis of the vessel wall. Erosion into the bronchi must almost certainly occur in many proximal aneurysms, given the frequency of fatal haemoptysis, but we found no other report of bronchoscopic detection of an aneurysm.

The current case is notable for its mimicry of a submucosal tumour. The bland, orangered bronchoscopic appearance belied the vascular nature of the lesion, unlike the more telltale, plexiform red pattern seen in well vascularised tumours such as a central carcinoid. Although transection of normal pulmonary vessels has been reported as a complication of transbronchial biopsy, ${ }^{4}$ such vessels are unlikely to protrude into the airway lumen.

Previous reports ${ }^{5}$ have cautioned against percutaneous biopsy of peripheral coin lesions without prior radiological examination, such as rapid sequence $\mathrm{CT}$ scan with contrast, to rule out aneurysms. This case suggests that similar caution needs to be extended to selected bronchoscopic procedures, and that the bronchoscopist would do well to add this lesion to the list of endobronchial masses in which a biopsy is to be assiduously avoided.

\section{Butto F, Lucas RV, Edwards JE. Pulmonary arterial aneurysm. A pathologic study of five cases. Chest 1987;91:237-41. \\ 2 Ungaro R, Saab S, Almond CH, Kumar S. Solitary periphera pulmonary artery aneurysms. Pathogenesis and surgica treatment. F Thorac Cardiovasc Surg 1976;71:566-71. \\ 3 St Christov V, Kanasirski P. Aneurysma des linken Haupastes der Arteria pulmonaris mit Ruptur in den linken Hauptbronchus. Zentralbl Alg Pathol 1966;109:524-6. \\ 4 Herf SM, Suratt PM. Complications of transbronchial lung biopsies. Chest 1978;Suppl 5:759-60. \\ 5 Eisenberg D, Gordon RL, Weineman EE, Romanoff $H$. Pulmonary artery aneurysm presenting as a peripheral coin lesion - the danger of needle biopsy. Cardiovasc Intervent Radiol 1984;7:280-2.}

\title{
Preoperative diagnosis of a pulmonary artery
} sarcoma

\section{Cardiovascular Surgery Unit $\checkmark$ Velebit $\mathrm{J}$ T Christenson \\ F Simonet \\ J Maurice \\ M Schmuziger}

\section{Department of Radiology} $\mathrm{H}$ Hauser

Hôpital de la Tour, 1217 Meyrin-Geneva, Switzerland

\section{Department of} Radiology, Hôpital Cantonal Universitaire, Geneva, Switzerland D Didier

Reprint requests to: Dr V Velebit.

Received 16 May 1994 Returned to authors 5 September 1994 Revised version received 6 October 1994 Accepted for publication 18 October 1994

\author{
V Velebit, J T Christenson, F Simonet, \\ J Maurice, M Schmuziger, H Hauser, \\ D Didier
}

\begin{abstract}
A pulmonary artery sarcoma was diagnosed preoperatively by magnetic resonance imaging enhanced with gadolinium and confirmed by percutaneous computed tomographic guided needle biopsy. Accurate preoperative diagnosis allowed planned curative surgery with removal of the right ventricular outflow tract and reconstructive surgery using a cryopreserved homograft.
\end{abstract}

(Thorax 1995;50:1014-1015)

Keywords: pulmonary artery sarcoma, diagnosis.

Pulmonary artery sarcoma is a rare tumour of the cardiovascular system, only about 120 cases having been reported. ${ }^{1}$ The tumour is most often mistaken for pulmonary embolism, ${ }^{2}$ and the surgical treatment may have to be improvised if the diagnosis is established only upon exploration of the pulmonary artery, which may lead to incomplete resection, palliative surgery, or imperfect reconstruction. ${ }^{3}$ The advantage of a precise preoperative diagnosis is obvious. We report a case of pulmonary artery sarcoma which was diagnosed preoperatively using two readily available radiological techniques that allowed planned and appropriate surgery.

\section{Case report}

A 37 year old man was admitted for suspected pulmonary embolism. He had voluntarily lost $7 \mathrm{~kg}$ in weight over the previous three months and presented with a dry cough and intermittent fleeting pain in the left chest. A chest radiograph showed reduced vascularisation of the left lung and a ventilation perfusion scan showed absence of perfusion to the left lung. The patient was not in distress and physical examination and blood gas analysis breathing air were normal. An ascending venogram showed no thrombi in the leg veins and vena cava. The pulmonary artery pressure was normal. A computed tomographic (CT) scan of the thorax confirmed the presence of an obstructed 


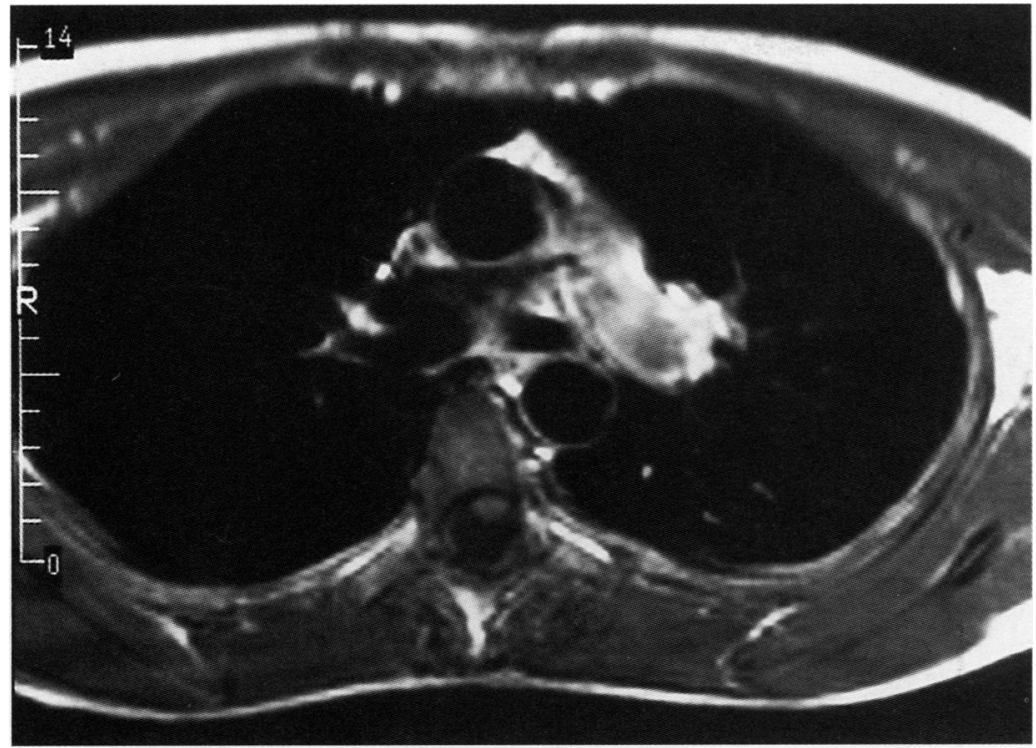

Gadolinium enhancement of the left pulmonary artery mass shown with magnetic resonance imaging.
Final pathological analysis confirmed the diagnosis of sarcoma of the pulmonary truncus totally obstructing the left pulmonary artery. The pulmonary masses seen on the CT scan were zones of pulmonary infarction.

\section{Discussion}

Only a few cases of sarcoma of the pulmonary artery have been diagnosed before resection. Fitzgerald ${ }^{4}$ described a needle biopsy of the pulmonary artery, but the histological findings were not diagnostic. Experience with this procedure is not extensive; however, the risk of bleeding from the thin walled pulmonary artery is minimal if it is totally occluded. A more recent report has described a diagnostic procedure similar to ours and definite preoperative diagnosis. 5

Magnetic resonance imaging (MRI) with gadolinium enhancement has been advocated for the diagnosis of malignancies and its value has previously been reported in a case of pulmonary artery sarcoma. ${ }^{6}$ It is increasingly being used for the evaluation of perfusion and metabolic activity of tissues. It has been limited by lack of a good contrast material to show neovascularisation, but this is now possible with gadolinium enhancement. We suggest that the combination of a perfusion lung scan, MRI, and CT guided needle biopsy provides a means of reaching the correct diagnosis preoperatively.

Pulmonary artery sarcoma has been treated surgically by several approaches including thoracotomy with pneumonectomy and "endarterectomy" of the tumour plug, ${ }^{7}$ or resection of the pulmonary artery using extracorporeal circulation and reconstruction with a valved conduit or a homograft. ${ }^{8}$ In view of the extension of the tumour in our case, we chose the latter approach which allowed wide excision of the tumour filled pulmonary artery. Even so, microscopic infiltration of the right section was found. For this reason, radiotherapy was given using multiple opposed fields to a CT constructed mediastinal target. There is no consensus on the efficacy of radiotherapy in this rare tumour, but it has been used in similar cases.

A precise preoperative diagnosis enables the best surgical approach and technique to be chosen, and allows time for ordering of prostheses or homografts which are not always readily available.

1 Krüger I, Borowski A, Host M, de Vivie ER, Gross-Fengels W. Symptoms, diagnosis and therapy of primary sarcomas
of the pulmonary artery. Thorac Cardiovasc Surg 1990;38: of the

2 Britton PD. Primary pulmonary artery sarcoma: a report of two cases, with special emphasis on the diagnostic problems. Clin Radiol 1990;41:92-4.

3 Promisloff RA, Segal SL, Lenchner GS, Cichelli AV, Wendell G, Aaronson G. Sarcoma of the pulmonary artery. Ches 1988;92:207-8.

4 Fitzgerald PM. Primary sarcoma of the pulmonary trunk: CT findings. $\mathcal{F}$ Comput Assist Tomogr 1983;7:521-3.

5 Bressler EL, Nelson JM. Primary pulmonary artery sarcoma. Diagnosis with CT, MR imaging and transthoracic needle biopsy. $A$ FR 1992;159:702-4.

6 Weinreb JC, Davis SD, Berkmen YM, Isom W, Naidich DP Pulmonary artery sarcoma: evaluation using GD-DTPA. $\mathfrak{f}$ Pulmonary artery sarcoma: evaluation

7 Redmond ML, Shepard JW, Gaffey TA, Payne WS. Primary Redmond ML, Shepard JW, Gaffey TA, Payne WS. Primary 1990;98:752-3

8 Head HD, Flam MS, John MJ, Lipnik SS, Slater DL, Stewart $\mathrm{RD}$. Long term palliation of pulmonary artery sarcoma by radical excision and adjuvant therapy. Ann Thorac Surg 1992;53:332-4. postoperative day. Echocardiography revealed a normally functioning homograft and no pulmonary regurgitation. Adjuvant radiation therapy was started six weeks later. 